\title{
Postoperative Pyoderma Gangrenosum in Association with Renal Cell Carcinoma and Chronic Lymphocytic Leukemia
}

\author{
Caius Solovan • Robert Smiszek • \\ Claudia Wickenhauser $\cdot$ Elena Chiticariu
}

To view enhanced content go to www.infectiousdiseases-open.com

Received: April 15, 2013 / Published online: June 11, 2013

(c) The Author(s) 2013. This article is published with open access at Springerlink.com

\section{ABSTRACT}

Introduction: Pyoderma gangrenosum (PG) is a rare sterile neutrophilic dermatosis characterized by painful recurrent ulcerations. It is frequently associated with inflammatory bowel disease, rheumatoid arthritis, or malignancies. PG is a diagnosis of exclusion, and it is based on clinical presentation, histology, history of an underlying disease, and exclusion of other causes of ulceration.

C. Solovan · E. Chiticariu ( $\varangle)$

Dermatology Department, University of Medicine and Pharmacy "Victor Babes", Timisoara Romania, Marasesti 5, 300077 Timisoara, Romania

e-mail: elena.chiticariu@yahoo.com

R. Smiszek

Urology Department, Helios Kliniken Leipziger

Land, Borna, Germany

C. Wickenhauser

Institute of Pathology, University of Leipzig,

Leipzig, Germany
Case Report: The authors report a 62-year-old male who developed a nonhealing ulcer at the site of incision following nephrectomy for renal cell carcinoma. Past medical history included chronic lymphocytic leukemia treated with rituximab. Histology of the skin lesion showed a phlegmonous nonspecific inflammation without being able to differentiate between a necrotizing wound infection and PG. The patient's condition was initially diagnosed as an infectious process and treated accordingly. After unsuccessful results with systemic antibiotics, high-dose corticosteroids induced prompt healing of the wound. On these bases, the diagnosis of postoperative PG within chronic lymphocytic leukemia and renal cell carcinoma was made.

Conclusion: Faced with postoperative necrotizing ulceration resistant to correctly administered antibiotics, PG must be considered. In such condition, the diagnosis must not be guided primarily by histology and early advice of a dermatologist is recommended.

Keywords: Chronic lymphocytic leukemia; Infectious diseases; Neutrophilic dermatosis; Pyoderma gangrenosum; Renal cell carcinoma; Ulceration 


\section{INTRODUCTION}

Pyoderma gangrenosum (PG) is a rare sterile inflammatory neutrophilic dermatosis characterized by recurrent painful ulcerations. Although the etiology is unclear, it is often associated with inflammatory bowel disease, rheumatoid arthritis or malignancies [1]. Recently, this condition was included in the group of cutaneous autoinflammatory disorders, characterized by defects in the innate immune response [2]. The name suggests an infectious agent but autoimmune mechanisms, neutrophil dysfunction, and disturbance of cellular immunity seem to be implicated. The accumulation of neutrophils in the skin lesions, similar with Sweet syndrome (acute febrile neutrophilic dermatosis) supporting the inclusion of PG within the spectrum of neutrophilic dermatoses [3]. The frequency of pathergy (development of new lesions or aggravation of existing ones following local injuries) suggests altered inflammatory responses to nonspecific stimuli. The widely accepted hypothesis is that PG has a complex and multifactorial pathogenesis, including genetic predisposition, paraneoplastic or para-immune phenomena, and undefined infectious agents $[4,5]$.

The most common clinical classification includes four major types: ulcerative, pustular, bullous, and vegetative [6, 7]. Other particular forms have also been described: peristomal, genital, mucosal, extracutaneous, and postoperative [8-11]. Herein, the authors present a patient with postoperative PG in association with renal cell carcinoma and chronic lymphocytic leukemia.

\section{CASE REPORT}

A 62-year-old male patient presented with renal carcinoma. The tumor was removed by partial nephrectomy in cold ischemia without undesirable events. Histology confirmed a well-differentiated renal cell carcinoma with histologically negative margins. The patient also suffered from stable chronic lymphocytic leukemia treated with rituximab and hypothyroidism under substitution with L-thyroxine.

Five days after nephrectomy, a progressive painful ulceration developed rapidly at the site of incision. The lesion was deep and had an overhanging violaceous border. The left lumbar area was indurated and erythematous (Fig. 1a).

The patient became febrile and his white blood cells (WBC) rose from 6,100 to 56,000/
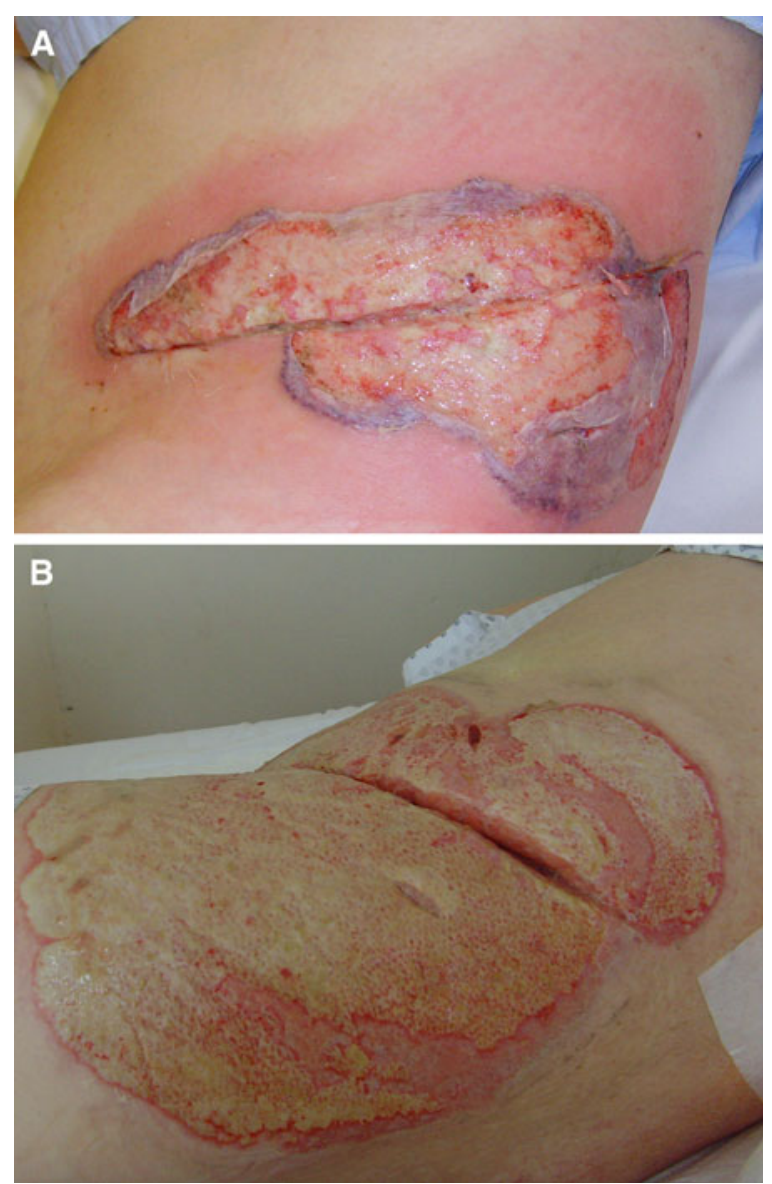

Fig. 1 Pyoderma gangrenosum: a extensive ulceration at the site of incision with violaceous borders at the periphery; b the ulceration after 12 days of corticotherapy 
$\mathrm{mm}^{3}$. C-reactive protein (CRP) levels increased from 1.4 to $259 \mathrm{mg} / \mathrm{L}$. At this point, a wound infection was suspected. He was empirically treated with antibiotics (ciprofloxacin, then imipenem and doxycycline) but its condition progressed relentlessly. Ultrasound and computer tomography scans failed to identify an abscess. Surgical wound revision did not identify any sign of bacterial infection. Preoperative, intraoperative, and postoperative wound culture remained negative. However, blood culture was positive for Staphylococcus haemolyticus, and imipenem was changed for vancomycin. Despite broad-spectrum antibiotics, there was a sustained expansion of the skin lesion. PG was suspected and the patient was referred to a dermatologist.

A biopsy specimen of the edge of the ulceration showed a phlegmonous nonspecific inflammation without being able to differentiate between a necrotizing wound infection and PG. Microbiology of the skin specimen was negative. Periodic acid schiff (PAS) staining was negative for fungal infection. There were no signs of vasculitis or malignancy. A second skin biopsy was performed. Histology showed a chronic granulomatous inflammation with subepithelial edema. A minimal focal inflammatory reaction affecting small and medium-sized vessels was identified in hypoderm (Fig. 2). Myeloperoxidase (MPOX) staining was positive (Fig. 3). CD79a (Fig. 4) and Epstein-Barr virus latent membrane protein-1 oncogene (EBV-LMP) were negative.

Taking into account the medical history, clinical features, histology, and lack of pathogens, the diagnosis of postoperative PG within chronic lymphocytic leukemia and renal cell carcinoma was made. The diagnosis of bacteremia with $S$. haemolyticus was also made.

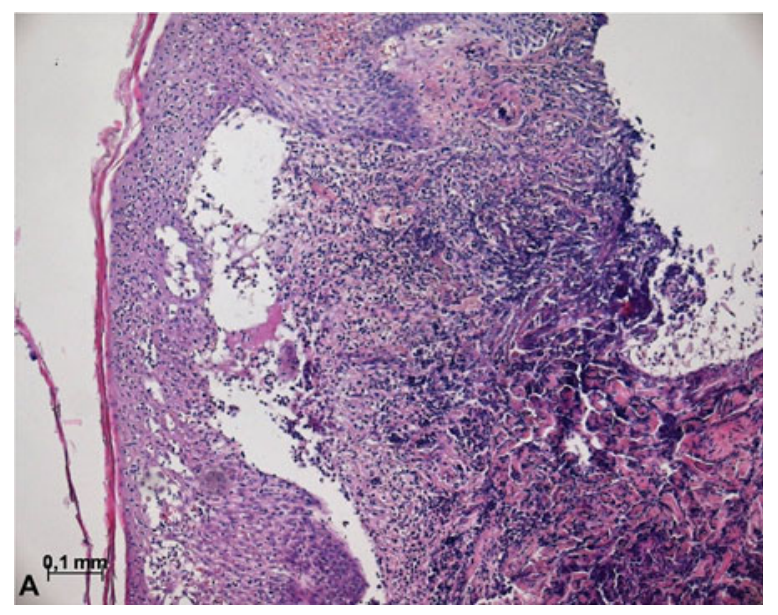

Fig. 2 Histology: haematoxylin and eosin staining of the vital edge of the dermal debridement with pronounced phlegmonous and granulomatous nonspecific inflammation approximating the deep dermis and the subcutaneous fat tissue

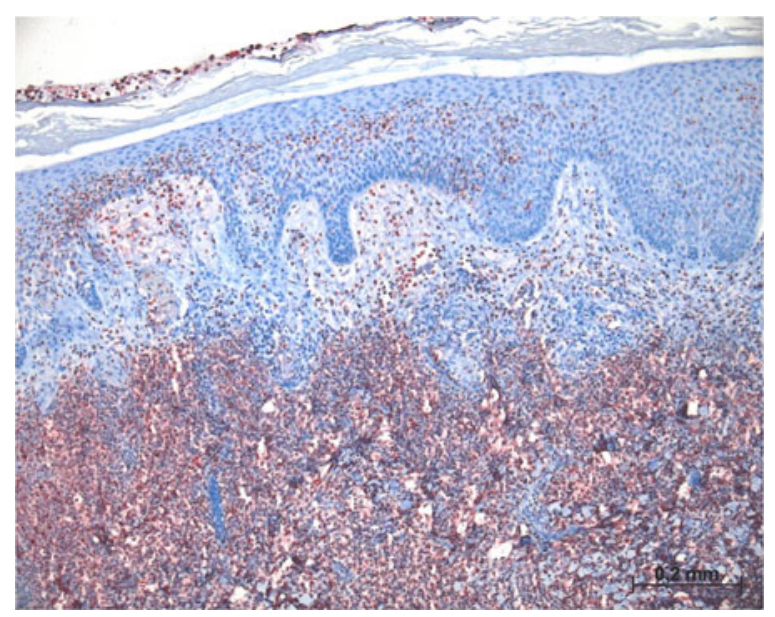

Fig. 3 Immunohistochemistry: the inflammatory infiltrate mostly consisted of myeloperoxidase positive granulocytes with only few concomitant lymphocytes

Therapy with high-dose prednisolone (250 mg/day) was initiated. The prednisolone therapy was gradually reduced and stopped after 3 weeks. Standard wound care consisted of polyhexanide applications and enzymatic debridement of necrotic tissue. After 2 weeks of treatment, WBC decreased to $6,000 / \mathrm{mm}^{3}$ and CRP to $47 \mathrm{mg} / \mathrm{L}$. The corticosteroids induced prompt healing of the wound (Fig. 1b). 


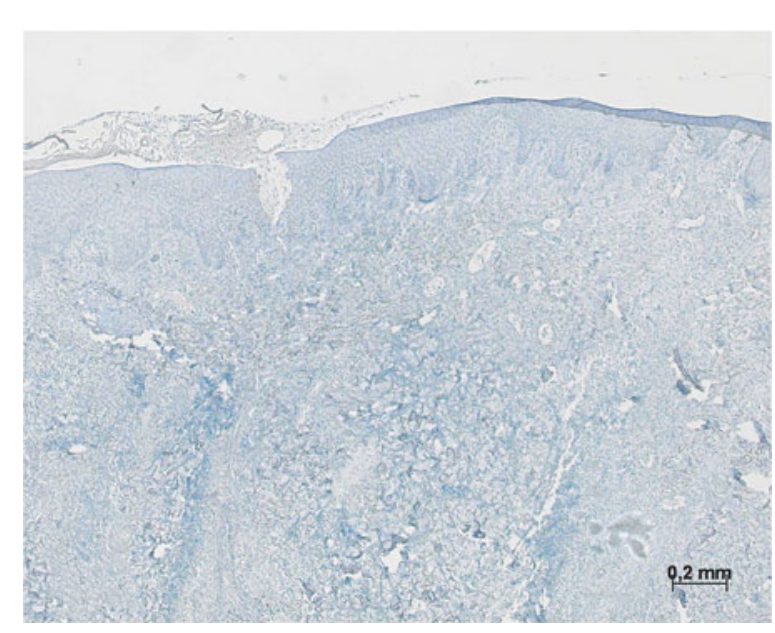

Fig. 4 Immunohistochemistry: no indication of an appreciable CD79a positive B-lymphoid cell population

Informed consent was obtained from the patient for being included in the study.

\section{DISCUSSION}

Postoperative PG was first described by Cullen in 1924 [12]; therefore, it is also known as postoperative progressive gangrene of Cullen. This entity is considered today as a variant of PG, similar to classical ulcerative form [13]. This form of PG begins as multiple small ulcerations several days to weeks after apparently normal healing [14]. It has been reported most often in association with abdominal and breast surgery, but it can complicate any invasive procedure [15]. Typical presentation is a primarily sterile ulcer several days after surgery, with rapid progression, lack of response to antibiotics and removal of necrotic tissue, and prompt healing after immunosuppressive agents [13].

This case is an excellent example of postoperative PG affecting a patient with two different types of malignancies simultaneously. The PG lesions have been initiated by surgical procedure, but the patient's status clearly played a significant etiopathogenetic role. The frequency of association between PG and malignancies is approximately $7 \%$ (in particular leukemia) [16]. More than half of all reported patients with PG in association with leukemia, presented acute myeloblastic leukemia with granulocytic maturation (M2), but chronic lymphocytic leukemia was also identified $[17,18]$. To the author's knowledge, PG was not reported in association with renal cell carcinoma, but it was reported in another patient receiving maintenance rituximab therapy for lymphoma [19].

The diagnosis of PG can be difficult. It depends upon a combination of clinical presentation, histology, history of underlying diseases, and exclusion of other conditions. Given the nonspecific histological findings and a positive blood culture for $S$. haemolyticus, it was very difficult to exclude a necrotizing wound infection. The leukocytosis in the absence of lymphocytosis cannot be explained by chronic lymphocytic leukemia or bacteremia. Cases of postoperative PG with leukaemoid reaction $\left(\mathrm{WBC}>50,000 / \mathrm{mm}^{3}\right.$ ) in the absence of hematologic malignancies have been reported [20, 21]. Despite a positive blood culture, the wound culture remained negative and the skin lesion responded to corticosteroids instead of antibiotics.

Similar features can be found in Fournier's gangrene, a rare but life threatening disease affecting patients with comorbidities, especially diabetes mellitus and alcoholism. It is a fulminant form of infective necrotising fasciitis affecting the perineal, genital, or perianal regions [22]. Wound culture is commonly positive for at least three organisms, including aerobes and anaerobes [23]. Fournier's gangrene requires an aggressive approach, including broad spectrum antibiotics, hemodynamic stabilization, and surgical debridement. It was highlighted that early surgical debridement is the first 
therapeutic intervention and has a major impact on the prognosis [24]. In contrast, surgical intervention can aggravate PG due to the pathergy phenomenon [25]. Other diseases to be considered in the differential diagnosis are malignancy, vasculitis, Sweet syndrome, or factitious ulcerations [1].

\section{CONCLUSION}

In conclusion, faced with postoperative necrotizing ulceration resistant to correctly administered antibiotics, PG must be considered in any case of apparently delayed wound healing. Since the most important findings suggestive for PG are painful ulcers with rapid outgrowth and undermined, violaceous borders in absence of infection, the diagnosis must not be guided primarily by histology and early advice of a dermatologist is recommended.

\section{ACKNOWLEDGMENTS}

This work was not supported financially or otherwise. Dr. Chiticariu is the guarantor for this article, and takes responsibility for the integrity of the work as a whole.

Conflict of interest. Dr. Solovan, Dr. Smiszek, Dr. Wickenhauser, and Dr. Chiticariu declare no conflict of interest.

Compliance with ethics guidelines. Informed consent was obtained from the patient for being included in the study.

Open Access. This article is distributed under the terms of the Creative Commons Attribution Noncommercial License which permits any noncommercial use, distribution, and reproduction in any medium, provided the original author(s) and the source are credited.

\section{REFERENCES}

1. Wollina U. Pyoderma gangrenosum-a review. Orphanet J Rare Dis. 2007;2:19.

2. Marzano AV, Ishak RS, Saibeni $S$, et al. Autoinflammatory skin disorders in inflammatory bowel diseases, pyoderma gangrenosum and sweet's syndrome: a comprehensive review and disease classification criteria. Clin Rev Allergy Immunol 2013 (Epub ahead of print).

3. Marzano AV, Cugno M, Trevisan V, et al. Role of inflammatory cells, cytokines and matrix metalloproteinases in neutrophil-mediated skin diseases. Clin Exp Immunol. 2010;162:100-7.

4. Brunsting LA, Goeckerman WH, O'Leary PA. Pyoderma gangrenosum: clinical and experimental observations in five cases occurring in adults. Arch Dermatol Syphilol. 1930; 22:655-80.

5. Ruocco E, Sangiuliano S, Gravina AG, et al. Pyoderma gangrenosum: an updated review. J Eur Acad Dermatol Venereol. 2009;23:1008-17.

6. Powell FC, Su WP, Perry HO. Pyoderma gangrenosum: classification and management. J Am Acad Dermatol. 1996;34:395-409.

7. Marzano AV, Tourlaki A, Alessi E, et al. Widespread idiopathic pyoderma gangrenosum evolved from ulcerative to vegetative type: a 10-year history with a recent response to infliximab. Clin Exp Dermatol. 2008;33:156-9.

8. Lyon CC, Smith AJ, Beck MH, et al. Parastomal pyoderma gangrenosum: clinical features and management. J Am Acad Dermatol. 2000; 42:992-1002.

9. Marzano AV, Ishak RS, Lazzari R, et al. Vulvar pyoderma gangrenosum with renal involvement. Eur J Dermatol. 2012;22:537-9.

10. McAleer MA, Powell FC, Devaney D, et al. Infantile pyoderma gangrenosum. J Am Acad Dermatol. 2008;58:S23-8.

11. Poiraud C, Gagey-Caron V, Barbarot S, et al. Cutaneous, mucosal and systemic pyoderma gangrenosum. Ann Dermatol Venereol. 2010;137:212-5.

12. Cullen TS. A progressively enlarging ulcer of the abdominal wall involving the skin and fat, 
following drainage of an abdominal abscess apparently of appendiceal origin. Surg Gynecol Obstet. 1924;38:579-82.

13. Schöfer H, Baur SJ. Successful treatment of postoperative pyoderma gangrenosum with cyclosporin. Eur Acad Dermatol Venereol. 2002;16:148-51.

14. Ouazzani A, Berthe JV, de Fontaine S. Post-surgical pyoderma gangrenosum: a clinical entity. Acta Chir Belg. 2007;107:424-8.

15. Gooding JM, Kinney TB, Oglevie SB, et al. Pyoderma gangrenosum twice complicating percutaneous intervention in a single patient. AJR Am J Roentgenol. 1999;172:1352-4.

16. Duguid CM, Powell FC. Pyoderma gangrenosum. Clin Dermatol. 1993;11:129-33.

17. Ho K, Otridge BW, Vanderberg E, et al. Pyoderma gangrenosum, polycythemia rubravera, and the development of leukemia. J Am Acad Dermatol. 1992;27:804-8.

18. Swale VJ, Saha M, Kapur N, et al. Pyoderma gangrenosum outside the context of inflammatory bowel disease treated successfully with infliximab. Clin Exp Dermatol. 2005;30:134-6.
19. Walsh M, Leonard N, Bell H. Superficial granulomatous pyoderma of the vulva in a patient receiving maintenance rituximab (MabThera) for lymphoma. J Low Genit Tract Dis. 2011;15:158-60.

20. Bryan CS. Fatal pyoderma gangrenosum with pathergy after coronary artery bypass grafting. Tex Heart Inst J. 2012;39:894-7.

21. Ryu J, Naik H, Yang FC, Winterfield L. Pyoderma gangrenosum presenting with leukemoid reaction: a report of 2 cases. Arch Dermatol. 2010;146:568-9.

22. Smith GL, Bunker CB, Dineeen MD. Fournier's gangrene. Br J Urol. 1998;81:347-55.

23. Thwaini A, Khan A, Malik A, et al. Fournier's gangrene and its emergency management. Postgrad Med J. 2006;82:516-9.

24. Elliott D, Kufera JA, Myers RA. The microbiology of necrotizing soft tissue infections. Am J Surg. 2000;179:361-6.

25. Callen JP, Jackson JM. Pyodermagangrenosum: an update. Rheum Dis Clin N Am. 2007;33:787-802. 